\section{MARKET STRATEGY AND ECONOMIC SURVIVAL}

Strategy and Market Structure

Competition, Oligopoly, and the Theory of Games. By Dr. Martin Shubik. Pp. xviii + 387. (New York: John Wiley and Sons, Inc.; London : Chapman and Hall, Ltd., 1959.) 64s. net.

IN 1944 there appeared "Theory of Games and Economic Behavior", the pioneer work by von Neumann and Morgenstern, full of promise for a uniform and dynamic theory of the firm on a new game-theoretic basis. In the subsequent fifteen years, game theory was developed and applied in many directions, but not to any effect in the theory of oligopoly and monopolistic competition, of the firm under various market conditions. What was sown in 1944 is at last bearing fruit, ample evidence being provided by this text by Dr. Shubik. It is possible to envisage now the bridging of that wide gap, disturbing to so many economists, between the traditional theory of the firm and practical business as understood by institutional economists and business schools. This is not to say that Dr. Shubik has constructed the bridge. His book is still rather severely theoretical. But he does take into account many factors which have hitherto been rather baffling - the influence of the financial strength of a firm, its technical position and its corporate formand he has so framed his theory that empirical work can be based upon it.

Dr. Shubik achieves two quite different objectives in dividing his book into two halves. In the first part he makes a game-theoretical exposition of existing theory and throws much new light on it. In a firm under pure competition or pure monopoly, the entrepreneur makes his decisions on his own and economic theory has long been able to handle the situation. Under what can be described either as oligopoly or as monopolistic competition, at least one firm in planning strategy on the market for a product must take into account the influence of at least one other firm on the same market. There is then a great variety of possible market structures, according to the varying number of firms and their different situations (for example, on transport costs), according to the extent of product differentiation, and according to the relative bargaining powers or market leadership of the firms. There is competition between firms but also co-operation, coalition and collusion. This is just the kind of situation to be exploited by game theory. Duopoly as analysed by Cournot and Edgeworth is such a special case that it cannot serve for generalization. The theory of monopolistic competition as elaborated by Chamberlin and Joan Robinson is piecemeal and lacking in the essential unifying principles. Dr. Shubik succeeds in his game-theoretical approach where the traditionalist development failed.

In the second part, Dr. Shubik attempts something even more important. This is a sketch of a truly dynamic theory of oligopoly, or rather the basis on which such a theory might well be built. He allows for imperfect information among the constituent firms on a market. His starting point is the concept of a particular type of game, the game of economic survival. A game of survival or ruin is well known as an extension of an ordinary zero-sum game, applied in successive periods until one player uses all his funds and is ruined. A game of economic survival is again a zero-sum game as long as the contestants survive (for example, splitting up a given market) but with a bonus to the ultimate survivor. On this view, the economic activity of the firm is to maximize something, generally the stream of dividends over time, but subject to attention being paid to survival. Not all the experts in this field go all the way with Dr. Shubik in his development of the theme, but none can deny that he is pursuing with great ingenuity something very well worth while. This is an important book, not only for game-theorists, but for all economists.

R. G. D. Allen

\section{THE DARK AGE IN AFRICA}

\section{Old Africa Rediscovered}

By Basil Davidson. Pp. $287+28$ plates. (London : Victor Gollancz, Ltd., 1959.) 25s. net.

$T$ HIS book is an attempt to accomplish the well-nigh impossible; but because the author knows a great deal about the late prehistory of many parts of Africa and can put down his knowledge in a clear and interesting manner, it is well worth perusal. It has been said that a few years ago such a work would have been impossible owing to lack of information; it can equally be said that a few years hence such a work will be quite impossible, except in the form of many volumes, because of too much data. At the same time, the reader should clearly understand the scope of the book. It is true that in the short introductories there is mention of pluvials, early lines of migrations, etc., but the author is not really concerned with very early times, his interests centring on the epoch from about 500 B.c. to the opening up of the continent by the Europeans.

As this is, perhaps, the period least understood in most African regions, the book will be very much welcomed. Of necessity the areas dealt with are somewhat scattered, but the account of the pre-Portuguese civilizations, which flourished along the east coast, and which Dr. Mathew has done so much to reconstruct, is of especial interest. Much, however, has not been included. The bulk of the rock-shelter art, at least in the Union of South Africa, falls within the author's period-indeed some of the finest of the polychromes probably date no farther back than the sixteenth century A.D. Pace one carbon dating, it is quite likely that the same applies to the Nachikufan culture of Northern Rhodesia at least in its later phases. This is indeed mentioned but discussed as dating to 4000 B.C. But the dating of early cultures in Africa is a notoriously controversial subject and need not be pursued further here.

It is true that the spine of the Sahara desert has been well-nigh impossible for human migration since Gamblian (last pluvial) times, but subsequent wet phases, the last one of no vast antiquity, have permitted human occupation in the fringes bordering the spine both on the north and the south, and once again much of the rock-shelter art in these regions belongs to Mr. Davidson's period. 'The description of the ancient town of Meroe with its great slag heaps and the Kush civilization is very well set out, and to many readers the account of Bernard Fagg's splendid pottery figurines from Nigeria which up to now have not been well published will be welcome indeed. Quite rightly, Dr. Manny's work in West Africa is 